Disponível em

http://www.anpad.org.br/rac

RAC, Rio de Janeiro, v. 19, n. 5, art. 1, pp. 544-564, Set./Out. 2015

http://dx.doi.org/10.1590/1982-7849rac20151794

$(\mathrm{cc}) \mathrm{E}$.

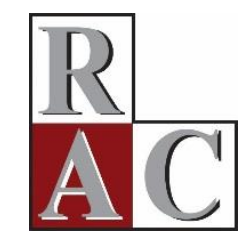

\title{
Carteiras Igualmente Ponderadas com Poucas Ações e o Pequeno Investidor
}

Equally Weighed Portfolios with Few Stocks and Small Investors

Diogo Carneiro Santiago

Lojas Americanas S. A.

Ricardo Pereira Câmara Leal Universidade Federal do Rio de Janeiro - UFRJ/Coppead 


\title{
Resumo
}

Este artigo analisa carteiras igualmente ponderadas $(1 / \mathrm{N})$ com foco no investidor sem sofisticação, com carteiras de pequenas de ações. A quantidade de ações incluídas nas carteiras 1/N foi de 6 a 16, e o rebalanceamento, feito apenas três vezes ao ano. O período de análise incluiu retornos diários e mensais, entre 1998 e 2011. O desempenho das carteiras 1/N foi comparado ao de fundos de investimento em ações (FIAs), a uma carteira de mínima variância global com limite de 10\% sobre os pesos positivos (MVP 10\%) e ao Ibovespa. As comparações empregaram testes não paramétricos, medidas de retorno ajustado ao risco e consideram custos de transação. Os resultados, por sua vez, indicam que os FIAs selecionados apresentam desempenho, na melhor das hipóteses, equivalente ao das carteiras $1 / \mathrm{N}$, apesar de apresentarem desvio padrão menor. Não se constatou retorno mediano das carteiras $1 / \mathrm{N}$ significativamente diferente do da Ibovespa e do da MVP 10\%. O critério de seleção das ações, segundo ordenamento pelo Índice de Sharpe do período anterior, é relevante, mas o rebalanceamento pode ser feito menos de três vezes ao ano. As carteiras 1/N são, portanto, uma alternativa atraente em relação aos FIAs para investidores com carteiras pequenas de ações, apesar de seus custos de transação poderem ultrapassar 400 pontos base por ano.

Palavras-chave: otimização de carteiras de investimento; relação retorno-risco; carteiras igualmente ponderadas; carteiras ingênuas; fundos de ações.

\begin{abstract}
This article analyzes equally-weighted stock portfolios $(1 / \mathrm{N})$ focusing on unsophisticated investors with small portfolios. The number of shares included in the $1 / \mathrm{N}$ portfolios ranged from 6 to 16 with rebalancing executed only three times a year. The period of analysis included daily and monthly returns between 1998 and 2011. The performance of the $1 / \mathrm{N}$ portfolios was compared to stock mutual funds, a global minimum variance portfolio with a 10\% limit on positive weights (MVP 10\%) and the Ibovespa index. The comparisons employed nonparametric tests, measures of risk-adjusted return and considered transaction costs. The results indicate that the performance of the selected funds is, at best, equivalent to the $1 / \mathrm{N}$ portfolios, albeit with a lower standard deviation. There was no significant difference in the median returns of the $1 / \mathrm{N}$ portfolios relative to the Ibovespa and MVP $10 \%$. The stock selection criterion according to the ranking by the previous period Sharpe ratio is relevant, but rebalancing may be carried out less than three times a year. The $1 / \mathrm{N}$ portfolios are an attractive alternative to stock funds for investors with small stock portfolios even though their transaction costs may exceed 400 basis points per year.
\end{abstract}

Key words: portfolio optimization; return-risk relationship; equally-weighted portfolios; naive portfolios; stock funds. 


\section{Introdução}

A participação de investidores individuais no mercado de ações tornou-se mais comum, mas pode ser difícil para a maioria deles gerir carteiras com muitas ações (Oliveira \& Paula, 2008). Swensen (2009) afirma que a distinção entre investidores capazes de gestão ativa e os demais é a mais importante, uma vez que o jogo custoso da gestão ativa de investimentos garante o fracasso dos demais, que são o foco deste artigo e aqui chamados de investidores sem sofisticação. Este trabalho compara o desempenho de carteiras pequenas formadas segundo critérios simples com fundos de investimentos em ações (FIAs) e uma carteira de mínima variância global (MVP), alternativas que se presumiram ao alcance do investidor sem sofisticação e com poucos recursos. Outra premissa é que o número de ações na carteira $(N)$ deve ser limitado para esse investidor.

Brito (1989) afirma que carteiras com 8 a 15 ações para investidores individuais e institucionais, respectivamente, poderiam eliminar boa parte da volatilidade da ação típica. Oliveira e Paula (2008) consideram os custos em uma carteira de $\mathrm{R} \$ 50.000$ de investidores individuais e afirmam que 6 ações reduzem o risco da carteira em 33\%, bem como que há equilíbrio entre custos e benefícios da diversificação, com 12 ações. Definiu-se, assim, uma carteira pequena como aquela com $N$ entre 6 e 16 e montante de $\mathrm{R} \$ 50.000$.

Kritzman, Page e Turkington (2010) elencam qualidades das carteiras com pesos uniformes (1/N), como evitar a concentração excessiva e capturar os efeitos de reversão à média no rebalanceamento, pois compram-se ações que desvalorizaram mais e vendem-se as que mais valorizaram. Estratégias 1/N supõem que o investidor não tem ou não quer usar o conhecimento existente sobre as ações consideradas em consonância com o caso do investidor sem sofisticação. Pflug, Pichler e Wozabal (2012) usam a teoria das escolhas racionais para demonstrar que as decisões ótimas de investimento tendem à estratégia de pesos uniformes para vários tipos de medidas de risco. Pflug et al. (2012) afirmam que esse é o caso nos problemas de otimização de carteiras e demonstram que, quando há incerteza sobre os retornos e também sobre sua distribuição, o que chamam de ambiguidade ou incerteza no sentido de Knight, a decisão ótima de investimento converge para carteiras $1 / \mathrm{N}$, à medida que a incerteza do modelo aumenta. Os autores alegam que padrões psicológicos que induzem o uso de pesos iguais ou enfoques que buscam uma explicação racional para isso são vertentes da literatura para explicar o sucesso dessa estratégia.

Duchin e Levi (2009) afirmam que as carteiras pequenas com pesos iguais desempenham melhor do que se forem otimizadas, segundo Markowitz (1952), ao contrário das grandes carteiras. DeMiguel, Garlappi e Uppal (2009) e Kritzman et al. (2010) alegam que modelos mais complexos precisam de estimativas derivadas de longas séries históricas (pelo menos 50 a 70 anos) para superar o problema do erro nas estimativas e gerar pesos estáveis, com menos valores extremos, e atingir desempenho melhor. A inexistência e potencial irrelevância econômica de séries históricas tão longas no Brasil representam uma limitação grave e dão respaldo teórico para a conjectura de que carteiras $1 / \mathrm{N}$ são uma alternativa interessante e de fácil implementação.

Essas considerações iniciais delineiam a motivação e a contribuição deste artigo aplicado ao investidor sem sofisticação com carteiras pequenas de ações. A hipótese é que uma carteira 1/N pequena é atraente para um investidor sem sofisticação em comparação a alternativas que estariam ao seu alcance, como a gestão passiva, representada pelo índice Ibovespa, a gestão ativa, representada pelos FIAs, e uma versão simples de carteira otimizada. A contribuição para a literatura nacional, naquilo que é verificável, consiste no foco sobre o investidor sem sofisticação, no tipo de veículo de investimento considerado na análise comparativa, e na consequente imposição de limites sobre a complexidade dos modelos empregados e o tamanho da carteira.

Este artigo não defende que o uso de carteiras $1 / \mathrm{N}$ supere modelos mais complexos, nem a análise fundamentalista de ações, ainda menos supõe que as técnicas que emprega sejam as melhores. Ao contrário, admite-se que métodos que usam melhor as informações históricas poderiam oferecer resultados mais interessantes, pois Santos e Tessari (2012) e Rubesam e Beltrame (2013) afirmam que 
carteiras ótimas formadas por meio de técnicas mais complexas superam as carteiras 1/N no Brasil. Esses autores, contudo, não focam no investidor sem sofisticação com carteira pequena, que dificilmente teria os recursos e a competência para empregar modelos mais complexos. Foge, portanto, ao escopo deste trabalho identificar o melhor modelo de otimização de carteiras de ações entre os muitos apresentados na literatura, como fizeram DeMiguel et al. (2009), porque seriam de difícil implementação por um investidor sem sofisticação.

O desempenho das carteiras 1/N $(6 \leq N \leq 16)$ equivale ao dos FIAs selecionados, e sugere que elas são uma alternativa atraente, apesar de seus custos de transação poderem ultrapassar 400 pontos base por ano. Somente dois dos FIAs selecionados apresentaram Índice de Sharpe (IS) maiores do que as carteiras $1 / \mathrm{N}$, embora todos tenham apresentado desvio padrão menor do que elas. Não houve diferença significativa entre as medianas dos retornos das carteiras $1 / \mathrm{N}$, o Ibovespa e uma MVP com limites de peso positivos de 10\% (MVP 10\%), proposta por Thomé, Leal e Almeida (2011). Há maior influência dos valores extremos diários nas carteiras $1 / \mathrm{N}$ e seus desvios padrão são maiores do que o da MVP 10\%. As carteiras 1/N também não apresentaram medidas de desempenho ajustado a riscos maiores do que a carteira MVP 10\%, sugerindo que o emprego de otimização e de métodos mais sofisticados, para aqueles investidores que têm qualificações e recursos para tal, pode ser relevante (Rubesam \& Beltrame, 2013; Santos \& Tessari, 2012).

É notável que uma estratégia simples como as carteiras $1 / \mathrm{N}$ possa apresentar IS maior do que o da maioria dos FIAs, particularmente quando se considera o amplo arsenal de técnicas disponíveis para os gestores profissionais. Contudo, esses resultados são constatações empíricas oriundas de um período específico e relativamente curto, cuja principal razão teórica pode ser o bem conhecido problema do erro nas estimativas e as incertezas inerentes a estimativas econômicas, como apontam Pflug et al. (2012).

A seção seguinte apresenta uma breve revisão da literatura. Ela é sucedida pela seção que descreve a metodologia, destacando os dados empregados, o critério de composição das carteiras, e os indicadores e testes usados para a comparação de desempenho. As duas seções seguintes apresentam os resultados principais e alguns testes de robustez, respectivamente, seguidas da seção final que conclui o estudo.

\section{Breve Revisão da Literatura}

Chance, Shynkevich e Yang (2011) e Bennet e Sias (2011) discordam do pensamento padrão em relação ao número de ativos ótimo para se obter a maior parte dos benefícios da diversificação, e argumentam que é incorreto supor que um pequeno número de ativos seja suficiente. DeMiguel et al. (2009) também acreditam que é necessário que $N$ seja grande para que uma carteira $1 / \mathrm{N}$ possa superar modelos de otimização de carteiras, uma vez que um $N$ elevado aumenta o potencial de diversificação. Chance et al. (2011) e Bennet e Sias (2011) não pretendem mostrar que é mais vantajoso ter uma carteira com $N$ muito grande, mas alertar para os perigos de o investidor acreditar que está bem diversificado com uma carteira com $N$ igual a 10 ou 15 ativos, por exemplo. Este artigo não aborda a questão da diversificação plena ao analisar carteiras $1 / \mathrm{N} \operatorname{com} N$ pequeno e não supõe que elas estejam bem diversificadas.

Um aspecto fundamental para o investidor que decide aplicar seu dinheiro em ações é a técnica a empregar para escolher os ativos e seus pesos na carteira. DeMiguel et al. (2009) sugerem que o uso da carteira $1 / \mathrm{N}$ oferece desempenho ajustado ao risco competitivo em relação a procedimentos mais sofisticados de alocação dos recursos. Eles compararam o desempenho de uma carteira $1 / \mathrm{N}$ com o de 14 modelos de formação de carteira que empregaram sete conjuntos de dados distintos provenientes dos EUA e de outros países. Seus resultados indicaram que nenhum dos modelos testados apresentou desempenho significativamente superior à carteira $1 / \mathrm{N}$. Os autores verificaram ser necessária uma janela de estimação de 3.000 meses para que uma carteira com 25 ativos, construída por meio de um modelo de média-variância, ou uma de suas extensões, superasse a carteira $1 / \mathrm{N}$. A janela aumentaria para 6.000 
meses para uma carteira de 50 ativos. Kritzman et al. (2010) mostram que modelos de otimização precisam obter parâmetros de séries históricas longas para superar a carteira $1 / \mathrm{N}$, e que séries mais curtas (5 a 10 anos) levam à superioridade da carteira $1 / \mathrm{N}$ devido ao erro nas estimativas.

A análise comparativa realizada neste artigo emprega a MVP com pesos limitados entre 0 e $10 \%$ para representar métodos mais complexos de seleção de carteiras. A MVP é a carteira mais à esquerda na fronteira eficiente, e que possui menor risco (Markowitz, 1952). Há razões práticas e teóricas para empregar a MVP com limites sobre os pesos. A MVP é a carteira ótima, cujos pesos podem ser estimados facilmente, sem depender dos retornos esperados e de recursos computacionais. A fórmula para seus pesos é $w=\left(\Sigma^{1} \times 1\right) /\left(\boldsymbol{1}^{T} \times \Sigma^{1} \times 1\right)$, onde $\boldsymbol{w}$ é o vetor de pesos, $\Sigma^{-1}$ é a matriz de variâncias e covariâncias invertida, $\boldsymbol{l}$ é um vetor unitário e $\boldsymbol{1}^{T}$ seu transposto. O investidor que conhecer a fórmula de cálculo dos pesos de uma MVP pode estimá-la sem necessidade de software especial, necessitando apenas da matriz de variâncias e covariâncias.

Carteiras de mínima variância sem restrições a venda a descoberto apresentam desempenho inferior à estratégia $1 / \mathrm{N}$ e a estratégias que restrinjam vendas a descoberto ou que imponham limites superiores aos pesos, ademais a imposição de restrições melhora o giro das carteiras (Behr, Guettler, \& Miebs, 2013; DeMiguel, Garlappi, \& Uppal, 2009; Thomé, Leal, \& Almeida, 2011). DeMiguel et al. (2009) constatam que a MVP com pesos positivos é o método que se sai melhor em comparação a outros 13 métodos de carteira ótima que analisam, deixando de superar apenas a carteira $1 / \mathrm{N}$ em quase todos os exercícios que realizaram.

A incerteza sobre os parâmetros de otimização e a severidade do problema do erro nas estimativas leva métodos desenvolvidos para lidar com essa dificuldade a obter um sucesso modesto quando comparados à limitação intuitiva dos pesos (DeMiguel et al., 2009; Pflug, Pichler, \& Wozabal, 2012). Os valores extremos remanescentes entre os pesos obtidos pelos métodos mais complexos afetam o desempenho das carteiras ótimas. Behr, Guettler e Miebs (2013) afirmam que a imposição de limites inferiores e superiores reduzem a influência dos erros nas estimativas sobre os pesos obtidos na otimização da MVP. Eles comparam MVP restritas a métodos mais complexos e à carteira $1 / \mathrm{N}$, e constatam que a MVP restrita apresenta IS mais elevados.

Kirby e Ostdiek (2012) afirmam que DeMiguel et al. (2009) colocaram as carteiras otimizadas em desvantagem em relação a carteiras $1 / \mathrm{N}$ ao usar metas de retorno muito altas que geraram carteiras agressivas, amplificaram o erro nas estimativas e aumentaram o giro. Aquelas carteiras não seriam superadas pela $1 / \mathrm{N}$ se a meta fosse ajustada ao seu retorno esperado antes de custos de transação. Fletcher (2011) apresenta evidência de carteiras otimizadas que superam a $1 / \mathrm{N}$ no Reino Unido. A evidência brasileira recente também favorece este tipo de carteiras. Thomé et al. (2011) analisaram carteiras MVP para as ações mais líquidas do Brasil, no período de janeiro de 1998 a dezembro de 2008, comparando-as com o desempenho do Ibovespa e de FIAs. Os autores não admitiram pesos negativos em sua análise e não encontraram diferenças de desempenho estatisticamente significativas entre a carteira MVP sem limites impostos sobre a participação positiva de cada ativo na carteira e o Ibovespa. Contudo, ao construir carteiras MVP com limites máximos impostos ao peso dos ativos, verificaram que a carteira com limite de peso de 10\% (MVP 10\%) apresentou desempenho superior ao do Ibovespa. Os autores também compararam a MVP $10 \%$ a carteiras $1 / \mathrm{N}$ formadas pelos mesmos ativos que compunham a carteira MVP sem limites sobre os pesos positivos. Seus resultados indicam que as carteiras 1/N apresentavam desempenho equivalente ao da carteira MVP 10\%. Thomé et al. (2011) não se preocuparam, contudo, em limitar $N$, que poderia chegar à quantidade de ações constituintes do Ibovespa, o que é um aspecto relevante para o investidor sem sofisticação que deseje gerir pequenas carteiras.

Santos e Tessari (2012) avaliaram carteiras de ações brasileiras por meio de três procedimentos de encolhimento (shrinkage), além da formação de carteiras por meio da matriz RiskMetrics, da matriz amostral de covariâncias e da carteira $1 / \mathrm{N}$. Eles concluíram que as carteiras que empregaram técnicas de otimização apresentaram desempenho ajustado a risco superior. Os autores empregaram as ações que constituíram o índice Ibovespa entre março de 2009 e novembro de 2011, e usaram rebalanceamentos diários, semanais e mensais, mas não se preocuparam em limitar $N$ a poucas ações. 
Rubesam e Beltrame (2013) usaram retornos diários entre junho de 1998 e junho 2011, e consideraram todas as ações existentes no mercado brasileiro até o momento de pararem de negociar, reduzindo o viés de sobrevivência. Eles empregaram quatro métodos para formação das matrizes de covariância para calcular MVPs: RiskMetrics, encolhimento, amostral e uma variante do modelo Generalized Autoregressive Conditional Heteroscedasticity (GARCH). As carteiras foram rebalanceadas a cada semana, mês e trimestre. As MVP, com matriz de covariâncias amostral, apresentaram retorno ajustado ao risco superior ao Ibovespa e a uma carteira $1 / \mathrm{N}$. Os autores empregaram diversos tamanhos de carteira entre 30 e o máximo possível, não contemplando carteiras com $N$ pequeno. Battaglia (2013), por outro lado, usou carteiras $1 / \mathrm{N}$ selecionadas aleatoriamente com $N$ igual a 10 com rebalanceamento trimestral e concluiu que elas superaram diversos FIAs de gestão ativa. Inclusive seus resultados também se mantêm para diversos períodos de rebalanceamento.

As diferenças entre os períodos amostrais, a frequência de rebalanceamento e de retornos e o número de ações considerado deixa dúvidas sobre a superioridade das carteiras $1 / \mathrm{N}$ com $N$ pequeno no país. Contudo, essas carteiras superaram o índice Ibovespa nos estudos de Thomé et al. (2011), Santos e Tessari (2012) e Rubesam e Beltrame (2013) e são indiscutivelmente mais simples de se formar do que carteiras que empregam métodos de otimização. Este artigo investigará, portanto, se carteiras com $N$ menor e rebalanceamento menos frequente do que o empregado por esses estudos brasileiros são atraentes para investidores sem sofisticação com carteiras de pequeno patrimônio.

\section{Metodologia}

\section{Dados}

$\mathrm{O}$ universo de ações considerado para formar as carteiras $1 / \mathrm{N}$ foi o das constituintes do Índice Ibovespa no início de cada quadrimestre, entre janeiro de 1998 e dezembro de 2011. O rebalanceamento das carteiras $1 / \mathrm{N}$ foi quadrimestral para seguir a formação das carteiras teóricas do Ibovespa, reduzir os custos e comparar os resultados com os de Thomé et al. (2011). Ademais, Battaglia (2013) mostrou que o desempenho ajustado ao risco de carteiras $1 / \mathrm{N}$ selecionadas aleatoriamente é pouco afetado para frequências de rebalanceamento mensal, bimestral, trimestral, quadrimestral, semestral e anual. O início do período de análise é o mesmo de Thomé et al. (2011) para permitir a comparação entre as carteiras formadas nos dois trabalhos. O final do período de análise corresponde ao último ano-calendário encerrado quando da decisão sobre os critérios de coleta dos dados. Os preços das ações foram ajustados para proventos (em particular, dividendos e juros sobre capital próprio). O imposto de renda (IR) e os custos de negociação com ações serão considerados em um teste de robustez na forma descrita na seção que sucede a que apresenta os resultados principais.

Primeiramente, foram identificadas as ações que compunham cada carteira quadrimestral do Ibovespa no sítio da Bolsa de Valores, Mercadorias e Futuros (BM\&FBovespa) na internet, entre janeiro de 1998 e dezembro de 2011. O número de ações no Ibovespa em cada quadrimestre no período amostral variou entre 45 (setembro 1999) e 69 (janeiro 2011). A média foi de 58 e a mediana de 57 ações, incluídas no Ibovespa no período. Sendo assim, a carteira $1 / \mathrm{N}$ com maior $N$ (16) variou entre 23 e $36 \%$ em relação ao total de ações no Ibovespa. Em seguida, foram obtidas as cotações diárias de fechamento dessas ações e do Ibovespa para os períodos em que faziam parte da carteira do Ibovespa na base de dados Economática®. Mudanças de códigos de ações, fusões ou cancelamentos ocorridos durante o período de análise foram verificados na base de dados da Bloomberg®. Não se evitou a inclusão de ações ordinárias e preferenciais da mesma empresa em uma carteira $1 / \mathrm{N}$ nos testes principais, mas isso foi praticamente eliminado no teste de robustez, em que se procurou a maior diversificação setorial possível. Os resultados com os dois critérios de formação de carteiras $1 / \mathrm{N}$ não apresentaram diferenças estatisticamente significativas. Obviamente, o investidor diversificaria mais se não incluísse duas ações da mesma empresa em sua carteira. 
As cotas líquidas diárias e demais informações dos FIAs foram obtidas da base de dados Quantum Axis ${ }^{\circledR}$ por meio de uma consulta realizada em maio de 2012 com os filtros de início anterior a maio de 1998, para fundos ativos em dezembro de 2011 e classificados pela Associação Brasileira das Entidades dos Mercados Financeiro e de Capitais (Anbima) como Ações Ibovespa Ativo, que usam o Ibovespa como benchmark e tentam superá-lo. Todos os 52 FIAs resultantes eram um condomínio do tipo aberto, e nove se destinavam a investidores qualificados. $O$ investidor sem sofisticação, com uma carteira pequena de ações, pode ser um investidor qualificado porque basta ter investimentos financeiros de pelo menos R\$ 300 mil. Desses nove fundos para investidores qualificados, dois seguiam as restrições dos reguladores previdenciários e de seguros para possibilitar investimentos de instituições desse segmento, mas estavam abertos para outros investidores qualificados, e três eram exclusivos e inacessíveis para investidores em geral, mas foram mantidos na amostra para comparação. Contudo, nenhum dos nove FIAs para investidores qualificados aparece entre os dez fundos com melhor retorno mediano diário usados nos testes comparativos.

O leitor interessado que fizer uma consulta com os mesmos filtros na base de dados Quanto Axis ${ }^{\circledR}$ no presente não obterá mais os mesmos FIAs obtidos em maio de 2012 porque houve alterações nos fundos depois disso, como mudanças de classificação, nome e liquidações. A série histórica de retornos dos FIAs usados neste trabalho pode ser obtida com o código de cada um deles na base de dados Quantum Axis ${ }^{\circledR}$, que preserva o histórico dos inativos. Uma lista com os códigos, características e mudanças nos 52 FIAs selecionados pode ser obtida com os autores.

\section{Critérios de formação de carteiras}

O Índice de Sharpe ex-post (IS), ao final de cada quadrimestre, foi empregado para escolher os $N$ ativos das carteiras ingênuas devido a seu uso corriqueiro e simples (Póvoa, 2010). A Equação 1 mostra a forma de cálculo do IS (Sharpe, 1966, 1994), em que o retorno da ação $i$ foi calculado com base nas suas cotações diárias de fechamento $\left(P_{i, t}\right)$, com ajuste de proventos e dividendos, na forma $R_{i, t}=P_{i, t} / P_{i, t-}$ ${ }_{1}-1, R_{f, t}$ é a taxa livre de risco representada pela taxa SELIC over diária e $s_{i}$ é o desvio padrão das diferenças diárias no numerador no quadrimestre.

$$
I S_{i}=\frac{\overline{\left(R_{l, t}-R_{f, t}\right)}}{s_{i}}
$$

As ações que compuseram o índice Ibovespa no segundo quadrimestre de 1998, por exemplo, foram selecionadas com base no IS calculado com os retornos diários de fechamento do primeiro quadrimestre de 1998. A carteira 1/N formada no segundo quadrimestre de 1998 foi a primeira por essa razão.

A liquidez é relevante para o investidor com carteiras pequenas e foi outro critério importante para a escolha das ações que compuseram a carteira de cada quadrimestre. As ações que não apresentaram cotação para todos os dias do quadrimestre anterior foram excluídas da carteira correspondente. As ações que não passaram por esse filtro, somadas aos casos de ações que não apresentaram histórico de cotação na base de dados Economática ${ }^{\circledR}$ no quadrimestre anterior, por motivo de cancelamento, atingiram um total de 213 exclusões em todo o período de análise, ou cerca de $6,8 \%$ do total de ações-quadrimestre. Uma ação pode ser excluída por falta de liquidez mais de uma vez, a cada rebalanceamento.

Foram construídas onze carteiras $1 / \mathrm{N}$ para cada período quadrimestral analisado, com $N$ variando de 6 a 16 ações. Assim, a carteira com $N$ igual a 10, por exemplo, é composta pelas ações com os dez maiores IS do período anterior, com pesos iguais a $10 \%$ para cada uma.

O critério para formar a carteira MVP 10\% foi o de Thomé et al. (2011), que empregaram a otimização de média-variância de Markowitz (1952) com os retornos das ações componentes do Ibovespa no quadrimestre anterior. Não foram admitidas vendas a descoberto e nem captação de empréstimos à taxa livre de risco. O peso máximo de $10 \%$ em cada ativo foi imposto como restrição. 


\section{Cálculo de retorno das carteiras}

O valor inicial de cada carteira ingênua foi arbitrado em 100. O valor de cada ativo em cada carteira $1 / \mathrm{N}$ é $100 / \mathrm{N}$ pontos, em que $N$ é o número de ações na carteira. No caso da MVP $10 \%$, o valor inicial de 100 pontos foi distribuído segundo os pesos derivados do procedimento de Markowitz (1952). Em seguida, o valor em pontos de cada ação foi dividido pelo preço de fechamento da ação no dia anterior ao da formação da carteira, determinando-se a quantidade teórica de cada ação na carteira. Para uma carteira $1 / \mathrm{N}$ com 10 ações, por exemplo, a cada ação $i$ corresponderiam 10 pontos e a quantidade teórica das ações na carteira seria igual a $Q_{i}=10 / P_{i, 1}$, onde $P_{i, 1}$ é o preço da ação $i$ no primeiro dia do quadrimestre. A quantidade teórica $Q_{i}$ permanece constante durante o quadrimestre. Ao final de todo dia $t$ do quadrimestre, a cotação de fechamento de cada ação da carteira $\left(P_{i, t}\right)$ foi multiplicada por $Q_{i}$ para se apurar o valor da carteira no dia $\left(V_{t}\right)$. A Equação 2 apresenta este cálculo.

$$
V_{t}=\sum_{i=1}^{N} P_{i, t} \times Q_{i}
$$

Esse procedimento foi repetido a cada quadrimestre, usando o valor em pontos da carteira no último dia do quadrimestre anterior como base para calcular a nova quantidade teórica de ações em cada carteira ingênua. Os retornos diários das carteiras $1 / \mathrm{N}\left(R_{p, t}\right)$ foram calculados na forma $V_{t} / V_{t-1}-1$ e usados para fazer as análises comparativas.

\section{Indicadores de desempenho das carteiras}

O IS de cada carteira foi calculado segundo a forma da Equação 1. Os alfas e betas de cada carteira foram obtidos por meio de regressões lineares, com o método dos mínimos quadrados ordinários, do prêmio de risco da carteira sobre o prêmio de risco de mercado para os 164 retornos mensais no período entre maio de 1998 e dezembro de 2011, conforme o modelo de mercado retratado na Equação 3. Essa equação é uma estimativa do Capital Asset Pricing Model (CAPM), cujo intercepto $\left(\alpha_{p}\right)$ deve ser nulo (Jensen, 1968). O gestor da carteira $p$ adiciona valor quando $\alpha_{p}$ é significativamente maior do que zero. Este coeficiente, quando interpretado dessa forma no contexto do CAPM, também é conhecido como alfa de Jensen (1968). Os demais elementos da Equação 3, sendo $t$, agora, um mês calendário, são: $R_{p, t}$, o retorno da carteira $p$ no mês $t ; R_{f, t}$, a taxa SELIC over no mês $t ; R_{m, t}$, o retorno do Ibovespa no mês $t$; $\beta_{p}$, o beta da carteira $p$ e $\varepsilon_{p, t}$, o resíduo da equação.

$$
\left(R_{p, t}-R_{f, t}\right)=\alpha_{p}+\beta_{p}\left(R_{m, t}-R_{f, t}\right)+\varepsilon_{p, t}
$$

Modigliani e Modigliani (1997) introduziram a razão M2 que calcula um alfa em relação ao mercado de uma carteira ajustada que consiste de uma proporção $x$ investida na carteira de interesse e o restante investido no ativo livre de risco. A proporção $x$ é determinada de forma que o desvio padrão da carteira ajustada seja igual ao do índice de mercado. A Equação 4 retrata M2 como a diferença entre o retorno médio da carteira ajustada, o termo entre colchetes, e o retorno médio do índice de mercado. A carteira ajustada investe uma proporção $\sigma_{m} / \sigma_{p}$ na carteira de interesse $p$ e $1-\sigma_{m} / \sigma_{p}$ no ativo livre de risco. $\bar{R}_{p}, \bar{R}_{f} e \bar{R}_{m}$ são os retornos médios mensais no período analisado da carteira de interesse, da taxa livre de riscos (taxa SELIC over no mês) e do mercado (Ibovespa), respectivamente, na Equação 4.

$$
M 2_{p}=\left[\frac{\sigma_{m}}{\sigma_{p}} \bar{R}_{p}+\left(1-\frac{\sigma_{m}}{\sigma_{p}}\right) \bar{R}_{f}\right]-\bar{R}_{m}
$$

A razão de Sortino, de uma carteira $p\left(S_{p}\right)$, é uma modificação do IS que considera apenas o downside risk em relação a uma meta de retorno, apresentada em sua forma mais conhecida em Sortino e Price (1994). A Equação 5 retrata $S_{p}$ e a Equação 6, o cálculo do downside risk $\left(\sigma_{D R}\right)$, onde $R_{p, t}$ é o retorno da carteira de interesse $p$ no mês $t, R_{m, t}$ é o retorno do Ibovespa no mês $t$, a meta de retorno, e $T$ é o número de retornos mensais na série temporal considerada.

$$
S_{p}=\frac{\overline{\left(R_{p, t}-R_{m, t}\right)}}{\sigma_{D R}}
$$




$$
\sigma_{D R}=\sqrt{\frac{\sum\left[\min \left(0, R_{p, t}-R_{m, t}\right)^{2}\right]}{T}}
$$

\section{Resultados Principais}

\section{Análise descritiva}

A Tabela 1 mostra as estatísticas descritivas de cada carteira 1/N para o período de maio de 1998 a dezembro de 2011. Não há diferença estatisticamente significativa entre as medianas das carteiras $1 / \mathrm{N}$ e a da MVP $10 \%$ ou do Ibovespa, embora os retornos acumulados e médios das carteiras $1 / \mathrm{N}$ as superem. A significância estatística das diferenças de desempenho foi estimada por meio do teste não paramétrico de postos com sinais de Wilcoxon. Levine, Stephan, Krehbiel e Berenson (2005) afirmam que este teste é mais eficaz do que o teste $t$ quando não se pode afirmar que os dados possuem distribuição normal. Ainda assim, o teste de Wilcoxon requer que as observações sejam independentes entre si, isto é, que a ocorrência de uma observação não afete a probabilidade de outra e, por isso, testes de autocorrelação serial foram usados para verificar essa exigência.

Tabela 1

Estatísticas Descritivas dos Retornos entre 5/1998 e 12/2011

\begin{tabular}{|c|c|c|c|c|c|c|c|c|c|}
\hline Carteira & $\begin{array}{c}\text { Acumulado } \\
(\%)\end{array}$ & $\begin{array}{c}\text { Média } \\
(\%)\end{array}$ & $\begin{array}{c}\text { Mediana } \\
(\%)\end{array}$ & $\begin{array}{l}\text { DP } \\
(\%)\end{array}$ & Curtose & Assimetria & $\begin{array}{c}\text { Mínimo } \\
(\%)\end{array}$ & $\begin{array}{c}\text { Máximo } \\
(\%)\end{array}$ & $\begin{array}{c}\text { Positivo } \\
\text { (\%) }\end{array}$ \\
\hline \multicolumn{10}{|c|}{ Retornos diários, 3385 observações } \\
\hline $1 / \mathrm{N}=6$ & 2778 & 0,14 & 0,14 & 2,97 & 435,83 & 12,35 & $-37,77$ & 102,20 & 53,80 \\
\hline $1 / \mathrm{N}=7$ & 2615 & 0,13 & 0,14 & 2,82 & 405,91 & 11,56 & $-36,02$ & 95,37 & 53,23 \\
\hline $1 / \mathrm{N}=8$ & 2448 & 0,13 & 0,12 & 2,68 & 367,73 & 10,60 & $-34,51$ & 88,66 & 53,00 \\
\hline $1 / \mathrm{N}=9$ & 1725 & 0,12 & 0,10 & 2,59 & 326,90 & 9,59 & $-33,39$ & 83,11 & 52,38 \\
\hline $1 / \mathrm{N}=10$ & 1820 & 0,12 & 0,12 & 2,52 & 303,07 & 9,00 & $-32,47$ & 79,21 & 53,18 \\
\hline $1 / \mathrm{N}=11$ & 1724 & 0,11 & 0,12 & 2,45 & 271,06 & 8,20 & $-31,06$ & 74,72 & 53,21 \\
\hline $1 / \mathrm{N}=12$ & 1742 & 0,12 & 0,15 & 2,40 & 246,60 & 7,59 & $-30,30$ & 71,43 & 53,53 \\
\hline $1 / \mathrm{N}=13$ & 1511 & 0,11 & 0,14 & 2,34 & 216,22 & 6,78 & $-29,43$ & 67,44 & 53,91 \\
\hline $1 / \mathrm{N}=14$ & 1456 & 0,11 & 0,13 & 2,29 & 190,47 & 6,15 & $-28,32$ & 63,66 & 54,09 \\
\hline $1 / \mathrm{N}=15$ & 1461 & 0,11 & 0,11 & 2,26 & 171,68 & 5,67 & $-27,53$ & 61,28 & 53,53 \\
\hline $1 / \mathrm{N}=16$ & 1477 & 0,11 & 0,13 & 2,23 & 158,53 & 5,29 & $-26,90$ & 59,23 & 53,74 \\
\hline MVP10\% & 1508 & 0,09 & 0,11 & 1,56 & 8,65 & $-0,10$ & $-11,11$ & 12,27 & 53,00 \\
\hline Ibovespa & 386 & 0,07 & 0,11 & 2,22 & 22,90 & 1,11 & $-15,83$ & 33,40 & 52,41 \\
\hline \multicolumn{10}{|c|}{ Retornos mensais, 164 observações } \\
\hline $1 / \mathrm{N}=6$ & 2778 & 3,32 & 1,64 & 22,85 & 116,98 & 9,86 & $-39,79$ & 271,34 & 65,24 \\
\hline $1 / \mathrm{N}=7$ & 2615 & 3,05 & 2,27 & 19,46 & 160,35 & 9,14 & $-36,83$ & 225,86 & 62,20 \\
\hline $1 / \mathrm{N}=8$ & 2448 & 2,88 & 1,84 & 17,34 & 95,40 & 8,39 & $-34,52$ & 196,03 & 62,80 \\
\hline
\end{tabular}




\section{Tabela 1 (continuação)}

\begin{tabular}{lccccccccc}
\hline Carteira & $\begin{array}{c}\text { Acumulado } \\
(\%)\end{array}$ & $\begin{array}{c}\text { Média } \\
(\%)\end{array}$ & $\begin{array}{c}\text { Mediana } \\
(\%)\end{array}$ & $\begin{array}{c}\text { DP } \\
(\%)\end{array}$ & Curtose & $\begin{array}{c}\text { Assimetria } \\
\text { Mínimo } \\
(\%)\end{array}$ & $\begin{array}{c}\text { Máximo } \\
(\%)\end{array}$ & $\begin{array}{c}\text { Positivo } \\
(\%)\end{array}$ \\
\hline $1 / \mathrm{N}=9$ & 1725 & 2,56 & 1,29 & 15,56 & 85,12 & 7,66 & $-32,59$ & 170,92 & 61,59 \\
$1 / \mathrm{N}=10$ & 1820 & 2,50 & 1,22 & 14,18 & 75,25 & 6,94 & $-30,81$ & 151,18 & 61,59 \\
$1 / \mathrm{N}=11$ & 1724 & 2,43 & 1,22 & 13,56 & 68,79 & 6,45 & $-30,48$ & 141,43 & 61,59 \\
$1 / \mathrm{N}=12$ & 1742 & 2,39 & 1,47 & 12,73 & 59,49 & 5,72 & $-30,16$ & 128,12 & 63,41 \\
$1 / \mathrm{N}=13$ & 1511 & 2,27 & 1,65 & 12,11 & 52,77 & 5,17 & $-30,60$ & 118,21 & 60,37 \\
$1 / \mathrm{N}=14$ & 1456 & 2,20 & 1,51 & 11,27 & 44,12 & 4,41 & $-32,20$ & 105,06 & 60,98 \\
$1 / \mathrm{N}=15$ & 1461 & 2,18 & 1,51 & 10,87 & 39,13 & 3,94 & $-33,02$ & 98,27 & 60,98 \\
$1 / \mathrm{N}=16$ & 1477 & 2,16 & 1,45 & 10,56 & 36,26 & 3,71 & $-31,99$ & 93,61 & 59,76 \\
MVP10\% & 1508 & 1,96 & 2,07 & 7,13 & 5,62 & $-0,31$ & $-30,18$ & 21,70 & 66,46 \\
Ibovespa & 386 & 1,39 & 1,43 & 8,99 & 5,19 & $-0,58$ & $-39,55$ & 24,05 & 56,71 \\
\hline
\end{tabular}

Nota. Acumulado é o retorno acumulado no período, DP é o desvio padrão e Positivo é o percentual de retornos positivos na série. MVP 10\% é a carteira de mínima variância global segundo o método de Markowitz com pesos dos ativos individuais limitados a $10 \%$. Testes de postos com sinais de Wilcoxon para a diferença entre o retorno mediano das carteiras $1 / \mathrm{N}$ e a MVP10\% e o Ibovespa não revelaram significância mesmo que marginal e foram omitidos.

Esses testes estatísticos foram omitidos da Tabela 1 por limitação de espaço, mas estão disponíveis com os autores. O teste de postos com sinais de Wilcoxon não revelou diferença significativa entre as medianas das carteiras 1/N tanto em relação à carteira MVP 10\% quanto ao Ibovespa. As estatísticas Jarque-Berra rejeitam a hipótese de normalidade de todas as séries, uma vez que são todas significativas ao nível de $1 \%$ e implicam que testes não paramétricos, tal como o de postos com sinais de Wilcoxon, deveriam ser preferidos (Levine, Stephan, Krehbiel, \& Berenson, 2005). As estatísticas Ljung-Box para a significância da autocorrelação para a primeira defasagem são significativas ao nível de $1 \%$ para todas as séries diárias de retornos, exceto a do Ibovespa. Contudo, não há significância nos níveis de 5 e $10 \%$ para as séries mensais de retornos. A consequência é que os resultados do teste de postos com sinais de Wilcoxon para as séries de retornos diários devem ser interpretados com cautela, mas a ausência de significância estatística do teste de Wilcoxon atenua essa preocupação.

Os retornos acumulados e médios das carteiras 1/N com menor número de ações são maiores, sem esquecer que os testes de diferença de medianas não revelaram significância estatística. A carteira 1/N com 10 ações, por exemplo, atingiu valor acumulado 4,7 vezes maior que o do Ibovespa e 1,2 vezes maior que o da MVP 10\%. As medianas dos retornos diários também mostram um quadro similar, mas a maioria das medianas dos retornos mensais das carteiras $1 / \mathrm{N}$ não supera a mediana da carteira MVP $10 \%$, o que sugere a influência dos valores extremos diários nas carteiras $1 / \mathrm{N}$. A ausência de diferenças significativas é consistente com Thomé et al. (2011) e Duchin e Levy (2009) para carteiras 1/N com N pequeno. Santos e Tessari (2012), Rubensan e Beltrame (2013), no Brasil, e Kirby e Ostdiek (2012) e Fletcher (2011), no exterior, encontram vantagens significativas para carteiras otimizadas em relação a carteiras 1/N com $N$ maior, o que não necessariamente conflita com os resultados aqui relatados que, porém, contrastam com DeMiguel et al. (2009), apesar desses autores analisarem carteiras 1/N com $N$ grande.

A Tabela 1 também mostra que as carteiras com $N$ menores foram as que tiveram mais valores extremos, com os maiores máximos e mínimos absolutos e curtoses elevadas. Todas as séries apresentaram mais retornos positivos do que negativos. Todas as distribuições de retornos diários das carteiras 1/N são assimétricas à direita, como já é bem conhecido em finanças, indicando maior frequência de retornos positivos. É interessante observar que o retorno mínimo mensal entre as carteiras $1 / \mathrm{N}$ com $N$ entre 10 e 12 é comparável ao da MVP 10\%. Por outro lado, os retornos máximos mensais são muito maiores para todas as carteiras $1 / \mathrm{N}$. 
O desvio padrão das carteiras $1 / \mathrm{N}$ cai à medida que aumenta o número de ativos na carteira. $\mathrm{A}$ diminuição marginal do desvio padrão das carteiras $1 / \mathrm{N}$ é maior para $N$ menores, como já é bem conhecido. Já o desvio padrão de todas as carteiras 1/N é maior do que o da MVP $10 \%$.

Embora as carteiras 1/N tenham oferecido retorno acumulado e médio maior do que o do Ibovespa e da MVP $10 \%$ no período da amostra, esse desempenho veio ao custo de mais volatilidade e, naturalmente, valores extremos. É interessante observar que os valores mínimos mensais são comparáveis aos da carteira MVP 10\%, enquanto que os diários são menores. Os valores máximos diários e mensais são muito maiores do que os da MVP 10\%. É possível que a disciplina imposta pelo rebalanceamento quadrimestral, segundo o IS, seja eficaz ao limitar o downside risk, mas o exame mais detalhado do retorno ajustado ao risco na próxima seção é necessário.

\section{Análise do retorno ajustado a risco}

A Tabela 2 mostra a análise com indicadores selecionados de desempenho ajustados ao risco para retornos mensais. Os resultados para retornos diários foram omitidos, mas serão comentados e estão disponíveis com os autores. Nenhum dos IS na Tabela 2 é significativamente diferente de zero. Os IS dos retornos diários também não são significativos. O maior IS dos retornos mensais na Tabela 2 é o da MVP 10\%. Sharpe (1994) mostra que o IS multiplicado pela raiz quadrada do número de observações equivale a uma estatística $t$ para a significância do diferencial de retornos no numerador do IS na Equação 1. Valores de IS que resultariam em diferenciais significativos ao nível de 5\% deveriam ser iguais ou maiores que $0,1531\left( \pm 1,96 \div 164^{0,5}\right)$ para os 164 retornos mensais e estatística $t$ igual a 1,96 para significância ao nível de 5\%. O IS significativo ao nível de 5\% deveria ser de 0,0337 para retornos diários. Os valores correspondentes para o valor crítico de $t$ ao nível de $10 \%$ são 0,1285 e 0,0283 para retornos mensais e diários, respectivamente.

Tabela 2

Desempenho Ajustado a Risco dos Retornos Mensais, entre 5/1998 e 12/2011

\begin{tabular}{lcccccc}
\hline Carteira & IS & Alfa & Beta & SQR & M2 & Sortino \\
\hline $1 / \mathrm{N}=6$ & 0,0888 & 0,0194 & 0,96 & 7,2150 & 0,0070 & 0,0882 \\
$1 / \mathrm{N}=7$ & 0,0904 & 0,0167 & 0,92 & 4,9814 & 0,0071 & 0,0921 \\
$1 / \mathrm{N}=8$ & 0,0917 & 0,0150 & 0,90 & 3,7785 & 0,0072 & 0,0940 \\
$1 / \mathrm{N}=9$ & 0,0817 & 0,0118 & 0,87 & 2,8987 & 0,0063 & 0,0832 \\
$1 / \mathrm{N}=10$ & 0,0853 & 0,0113 & 0,84 & 2,3076 & 0,0067 & 0,0881 \\
$1 / \mathrm{N}=11$ & 0,0841 & 0,0106 & 0,85 & 2,0059 & 0,0066 & 0,0876 \\
$1 / \mathrm{N}=12$ & 0,0864 & 0,0102 & 0,85 & 1,6561 & 0,0068 & 0,0913 \\
$1 / \mathrm{N}=13$ & 0,0809 & 0,0090 & 0,84 & 1,4251 & 0,0063 & 0,0857 \\
$1 / \mathrm{N}=14$ & 0,0807 & 0,0083 & 0,84 & 1,1187 & 0,0063 & 0,0862 \\
$1 / \mathrm{N}=15$ & 0,0819 & 0,0080 & 0,83 & 0,9866 & 0,0064 & 0,0883 \\
$1 / \mathrm{N}=16$ & 0,0824 & 0,0079 & 0,82 & 0,8998 & 0,0064 & 0,0895 \\
MVP10\% & 0,0940 & 0,0061 & 0,65 & 0,2619 & 0,0074 & 0,1169 \\
Ibovespa & 0,0111 & - & 1,00 & - & - & 0,0000 \\
\hline
\end{tabular}

Nota. O número de observações é igual a 164. O Índice de Sharpe (IS) foi definido na Equação 1. Nenhum IS é significativo ao nível de 5\% (valor crítico igual a 0,1531). O alfa e o beta foram definidos na Equação 3. SQR é a soma dos quadrados dos resíduos definidos na Equação 3. O M2 foi definido pela Equação 4 e a razão de Sortino, pela Equação 5. Nenhum dos IS reflete um diferencial de retornos no numerador significativamente diferente de zero ao nível de 5\%. Nenhum alfa é significativo ao nível de 5\%, embora os alfas das carteiras com $N$ igual a 6,7 e 8 e da carteira MVP $10 \%$ sejam significativos ao nível de $10 \%$. Todos os betas são significativos ao nível de 1\%. MVP 10\% é a carteira de mínima variância global segundo o método de Markowitz (1952) com pesos dos ativos individuais limitados a $10 \%$. 
Todos os betas das carteiras $1 / \mathrm{N}$ são significativos ao nível de $1 \%$ e se situam entre 0,82 e 0,96. O beta da carteira MVP $10 \%(0,65)$ é mais baixo do que os das carteiras $1 / \mathrm{N}$. O risco sistemático destas carteiras é mais alto do que o daquela. Apenas os alfas das carteiras com $N$ igual a 6,7 e 8 e da carteira MVP 10\% apresentaram significância ao nível de 10\%. Os alfa de Jensen de todas as carteiras ficaram abaixo de 194 pontos-base, com retornos mensais $(1,94 \%)$, e de 7 pontos-base $(0,07 \%)$, com retornos diários.

O M2 é uma espécie de alfa para carteiras ajustadas ao mesmo nível de risco total (desvio padrão). O maior valor é o da carteira MVP 10\%, ficando sempre abaixo de 74 pontos-base para retornos mensais e 5 pontos-base para retornos diários nas carteiras $1 / \mathrm{N}$. Todas as carteiras geram retornos excessivamente baixos quando ajustados ao risco. Finalmente, a razão de Sortino, que é um IS que considera apenas o downside risk, é maior para a MVP 10\%. Os resultados dos indicadores de desempenho ajustados ao risco sugerem superioridade para a carteira MVP 10\%, e são consistentes com as conjecturas de Behr et al. (2013) e Pflug et al. (2012) de que limites sobre os pesos de carteiras otimizadas podem lidar de maneira razoável com o problema do erro nas estimativas decorrentes da incerteza sobre os retornos e a sua distribuição.

A Tabela 3 apresenta um retrato do IS das diversas carteiras segundo períodos discretos e não superpostos do calendário, e também para janelas rolantes de tempo. Considerando os períodos discretos, todas as carteiras 1/N superaram o Ibovespa em um número de meses significativamente diferente do que a metade de meses no período da amostra, segundo uma distribuição binomial (veja detalhes na nota da Tabela 3$)$, mas somente quatro delas ( $N$ entre 11 e 14) superaram o Ibovespa significativamente em mais quadrimestres do que a metade dos quadrimestres no período amostral, e nenhuma delas na frequência anual. A Tabela 3 revela que não há frequência de desempenho superior para os períodos discretos em relação à carteira MVP10\%, o que é consistente com a maior volatilidade e assimetria à direita das carteiras $1 / \mathrm{N}$ e com a ausência de desempenho superior sugeridas pelo teste estatístico e pelos retornos ajustados a risco na Tabela 2. Os resultados com as janelas rolantes de tempo são similares aos apresentados com períodos discretos, mas não oferecemos análise de significância estatística para essas janelas porque elas são superpostas, gerando amostras sem independência.

Tabela 3

Percentual de Períodos em que o IS das Carteiras 1/N foi Superior, entre 5/1998 e 12/2011

\begin{tabular}{lcccccccccccc}
\hline Tam. Janela & $\mathbf{N}^{\mathbf{0}}$ Per & $\mathbf{N = 6}$ & $\mathbf{7}$ & $\mathbf{8}$ & $\mathbf{9}$ & $\mathbf{1 0}$ & $\mathbf{1 1}$ & $\mathbf{1 2}$ & $\mathbf{1 3}$ & $\mathbf{1 4}$ & $\mathbf{1 5}$ & $\mathbf{1 6}$ \\
\hline \multicolumn{1}{l}{ Ibovespa em janelas fixas e não superpostas } \\
\hline Mês & 164 & $57^{*}$ & $59^{*}$ & $59^{*}$ & $55^{*}$ & $55^{*}$ & $59^{*}$ & $60^{*}$ & $59^{*}$ & $58^{*}$ & $57^{*}$ & $54^{*}$ \\
Quadrimestre & 41 & 59 & 56 & 56 & 59 & 56 & $61^{*}$ & $61^{*}$ & $66^{*}$ & $61^{*}$ & 59 & 59 \\
Ano & 14 & 50 & 50 & 57 & 50 & 64 & 64 & 64 & 57 & 57 & 57 & 57 \\
\hline Ibovespa em janelas rolantes que se movem 1 dia por vez, superpostas & & & & & & \\
\hline 21 dias & 3365 & 54 & 57 & 57 & 56 & 56 & 56 & 57 & 56 & 56 & 56 & 56 \\
84 dias & 3302 & 55 & 58 & 59 & 59 & 63 & 62 & 63 & 63 & 63 & 64 & 65 \\
252 dias & 3134 & 65 & 66 & 71 & 71 & 74 & 74 & 75 & 73 & 71 & 70 & 64 \\
\hline MVP 10\% em janelas fixas e não superpostas & & & & & & & & & \\
\hline Mês & 164 & 49 & 49 & 48 & 48 & 48 & 48 & 49 & 48 & 48 & 47 & 49 \\
Quadrimestre & 41 & 49 & 49 & 49 & 49 & 49 & 51 & 51 & 46 & 44 & 44 & 44 \\
Ano & 14 & 57 & 57 & 57 & 43 & 36 & 43 & 43 & 43 & 43 & 43 & 50 \\
\hline
\end{tabular}


Tabela 3 (continuação)

\begin{tabular}{lcccccccccccc}
\hline Tam. Janela & $\mathbf{N}^{\mathbf{0}}$ Per & $\mathbf{N = 6}$ & $\mathbf{7}$ & $\mathbf{8}$ & $\mathbf{9}$ & $\mathbf{1 0}$ & $\mathbf{1 1}$ & $\mathbf{1 2}$ & $\mathbf{1 3}$ & $\mathbf{1 4}$ & $\mathbf{1 5}$ & $\mathbf{1 6}$ \\
\hline \multicolumn{2}{l}{ MVP 10\% em janelas rolantes que se movem } & 1 & dia & por vez, superpostas & & & & & \\
\hline 21 dias & 3365 & 49 & 50 & 50 & 49 & 49 & 48 & 48 & 48 & 48 & 48 & 48 \\
84 dias & 3302 & 50 & 51 & 49 & 46 & 47 & 45 & 47 & 46 & 46 & 46 & 46 \\
252 dias & 3134 & 52 & 52 & 53 & 45 & 48 & 48 & 48 & 44 & 43 & 43 & 46 \\
\hline
\end{tabular}

Nota. Tam. Janela é a duração das janelas: um mês, quadrimestre e ano do calendário para as fixas e 21, 84 e 252 dias de negociação para as rolantes. $\mathbf{N}^{\mathbf{0}}$ Per. é o número de janelas. MVP 10\% é a carteira de mínima variância global segundo o método de Markowitz (1952), com pesos dos ativos individuais limitados a 10\%. As carteiras 1/N deveriam superar a carteira alternativa (Ibovespa ou MVP 10\%) pelo menos em 87 meses, 25 quadrimestres ou 11 anos para que o número de superações com janelas fixas fosse significativo ao nível de $5 \%$, segundo a distribuição binomial dada por $p(X)=\left(N ! /(X ! \times(N-X) !) \times p^{X} \times\right.$ $(1-p)^{N-X}$, em que $N$ é o número de períodos e $X$ o número de sucessos, isto é, o número de períodos em que a carteira $1 / \mathrm{N}$ superou a carteira alternativa, $p$ é igual 0,5 e $p(X)$ é a probabilidade de $X$, no caso no máximo $5 \%$. A estatística não foi calculada para as janelas rolantes porque elas são superpostas.

* Indica significância ao nível de 5\%.

Em resumo, a análise dos indicadores de desempenho ajustados ao risco não sugere superioridade das carteiras 1/N em relação à carteira MVP 10\%. Nenhuma delas apresenta IS significativo e maior do que o da carteira MVP 10\%, e todas elas apresentam risco sistemático maior do que o da carteira MVP $10 \%$. Os alfas apresentados pelas carteiras $1 / \mathrm{N}$ não são significativamente diferentes de zero e vêm ao custo de maior risco não sistemático. Os indicadores M2 e Sortino são superiores para a carteira MVP $10 \%$. A evidência apresentada é consistente com a de artigos nacionais que usaram carteiras $1 / \mathrm{N}$ com $N$ maior e rebalanceamento mais frequente, como Thomé et al. (2011), Santos e Tessari (2012) e Rubesam e Beltrame (2013), e com a afirmativa de DeMiguel et al. (2009) de que o valor de $N$ deve ser grande para que as carteiras $1 / \mathrm{N}$ apresentem desempenho superior aos oferecidos por carteiras formadas por meio de técnicas de otimização. Além disso, a imposição de limites sobre os pesos também parece ser uma forma razoável para se lidar com o problema do erro nas estimativas, em consonância com Behr et al. (2013) e Pflug et al. (2012). Embora os investidores que empreguem carteiras $1 / \mathrm{N}$ tenham chances de superar o Ibovespa, eles terão chances muito menores de superar uma carteira de mínima variância formada segundo a otimização clássica de Markowitz com desvios padrão e correlações históricas.

\section{Análise comparativa aos FIAs}

Os FIAs representam a principal alternativa de investimento em ações para investidores sem sofisticação, e é importante verificar como as carteiras $1 / \mathrm{N} \operatorname{com} N$ pequeno se comportaram em relação a eles. Os testes de postos com sinais de Wilcoxon para a diferença entre o retorno mediano de todas as carteiras $1 / \mathrm{N}$ e cada um dos 52 FIAs selecionados não indicaram diferenças significativas entre as medianas das séries de retornos dos FIAs e as das carteiras 1/N. Os 52 FIAs selecionados não conseguiram superar com significância estatística as carteiras 1/N no período entre maio de 1998 e dezembro de 2011. A Tabela 4 apresenta um resumo dos resultados para os dez FIAs de maior retorno mediano. 
Tabela 4

Desempenho de FIAs Selecionados Segundo Retornos Diários, entre 5/1998 e 12/2011

\begin{tabular}{cccccccccc}
\hline FIA & $\begin{array}{c}\text { Mediana } \\
(\%)\end{array}$ & $\begin{array}{c}\text { Média } \\
(\%)\end{array}$ & $\begin{array}{c}D P \\
(\%)\end{array}$ & $\begin{array}{c}\text { Acumulado } \\
(\%)\end{array}$ & $I S$ & $I S, N 06$ & \multicolumn{2}{c}{$I S, N 16$} & \multicolumn{2}{c}{ Wilcoxon } & Wilcoxon \\
& 0,1557 & 0,0824 & 1,93 & 765 & 0,0116 & $-0,0204$ & $-0,0126$ & $-1,49$ & $-1,55$ \\
\hline 1 & $0,06=16$ \\
2 & 0,1454 & 0,0807 & 2,01 & 674 & 0,0102 & $-0,0212$ & $-0,0139$ & $-1,15$ & $-1,18$ \\
3 & 0,1428 & 0,1159 & 1,72 & 2972 & $0,0325^{*}$ & $-0,0071$ & 0,0047 & $-1,06$ & $-1,09$ \\
4 & 0,1417 & 0,0953 & 1,60 & 1529 & 0,0220 & $-0,0154$ & $-0,0052$ & $-1,02$ & $-1,05$ \\
5 & 0,1410 & 0,0737 & 1,98 & 525 & 0,0069 & $-0,0236$ & $-0,0172$ & $-1,00$ & $-1,02$ \\
6 & 0,1380 & 0,0692 & 1,89 & 469 & 0,0048 & $-0,0258$ & $-0,0206$ & $-0,90$ & $-0,92$ \\
7 & 0,1359 & 0,1166 & 2,00 & 2526 & 0,0282 & $-0,0077$ & 0,0061 & $-0,83$ & $-0,85$ \\
8 & 0,1355 & 0,0821 & 1,97 & 734 & 0,0112 & $-0,0206$ & $-0,0129$ & $-0,82$ & $-0,83$ \\
9 & 0,1354 & 0,0867 & 1,96 & 897 & 0,0137 & $-0,0191$ & $-0,0105$ & $-0,82$ & $-0,83$ \\
10 & 0,1341 & 0,0756 & 1,93 & 586 & 0,0080 & $-0,0231$ & $-0,0167$ & $-0,77$ & $-0,78$ \\
\hline
\end{tabular}

Nota. Retornos diários (3385 observações). Fundos: (1) Fator Jaguar; (2) Itaú Private Ativo; (3) Próspero Adinvest; (4) Fama Challenger; (5) Safra Private; (6) Safra Ações; (7) Opportunity Lógica II; (8) Santander Institucional BR Ibovespa; (9) Bradesco Private Alavancado Ibovespa; (10) Santander Plus. DP é o desvio padrão, Acumulado é o retorno acumulado no período e IS é o Índice de Sharpe definido na Equação 1. IS, N06 e IS, N16 são o IS calculado com o retorno médio das carteiras 1/N N06 e N16 em lugar da taxa livre de riscos. O módulo do IS significativo deveria ser de 0,0337 e 0,0283 para retornos diários ao nível de significância de $5 \%$ e $10 \%$, respectivamente. Wilcoxon é o teste de postos com sinais de Wilcoxon para a diferença entre o retorno mediano do fundo e o das carteiras 1/N N06 e N16 mostrados na Tabela 1. Nenhum dos testes de Wilcoxon ou IS relativo a carteiras $1 / \mathrm{N}$ é significativo ao nível de $5 \%$ ou $10 \%$.

* Indica significância ao nível de $10 \%$.

O IS retratado na Equação 1 foi calculado para cada FIA com o retorno diário da carteira $1 / \mathrm{N}$ de interesse $(N=6$ ou 16) no lugar da taxa livre de riscos, usando como denominador o desvio padrão da diferença diária entre o retorno do FIA e da carteira $1 / \mathrm{N}$ de interesse. O valor resultante desse cálculo, multiplicado pela raiz quadrada do número de observações diárias (3385), equivale a uma estatística $t$ que indica desempenho significativamente diferente do FIA em relação à carteira $1 / \mathrm{N}$ escolhida. Nenhum FIA apresentou significância em relação às carteiras 1/N com 6 ou 16 ações. Os valores de IS que resultariam em diferenciais significativos são os mesmos empregados na seção anterior, uma vez que o número de observações é o mesmo. Os valores correspondentes para o valor crítico de $t$ ao nível de 5\% são 0,1531 e 0,0337 para retornos mensais e diários, respectivamente, e de 0,1285 e 0,0283 para retornos mensais e diários, também respectivamente, ao nível de $10 \%$ de significância. O desempenho dos FIAs, na melhor das hipóteses, equivale ao das carteiras $1 / \mathrm{N}$, o que representa um resultado preocupante para os investidores em FIAs.

Considerando a facilidade de seu critério de formação para investidores sem sofisticação, que não demanda o entendimento da otimização de Markowitz (1952) nem de técnicas de análise, os resultados obtidos sugerem que a alocação $1 / \mathrm{N}$ poderia ter sido uma alternativa razoável para esses investidores em relação aos FIAs. Embora haja alguns FIAs que superaram as carteiras 1/N em termos de retorno acumulado, sem significância estatística para o IS, é difícil para o investidor selecionar, a priori, fundos vencedores.

Finalmente, cabe dizer que os retornos dos FIAs foram calculados a partir das cotas reportadas, que são líquidas das taxas de administração e performance, e ajustados para se aproximarem de retornos brutos, uma vez que os retornos das carteiras $1 / \mathrm{N}$ também eram brutos. A recomposição das taxas de administração foi feita por meio da Equação 7, onde $C A_{t}$ é a cota ajustada do FIA no dia $t, C_{t}$ a cota reportada do FIA no dia $t$ e $f$ a taxa de administração do FIA no último dia de análise do período. A cota 
empregada no primeiro dia da série foi a não ajustada (reportada). Somente 11 dos 52 FIAs apresentaram taxas de performance, mas sua recomposição não foi calculada por ser mais complexa.

$$
C A_{t}=C A_{t-1} \times \frac{C_{t}}{C_{t-1}} \times\left(1+\frac{f}{252}\right)
$$

\section{Testes de Robustez}

A formação de carteiras $1 / \mathrm{N}$ com $N$ pequeno pode ser realizada segundo diversos critérios. Os testes de robustez envolveram reordenar as ações presentes nas carteiras 1/N do menor para o maior IS; excluir tanto quanto possível ações do mesmo setor de atividade; atribuir pesos diferentes às ações nas carteiras, sem usar otimização; e reduzir o número de rebalanceamentos. Além disso, foram considerados tributos e custos de transação. Os resultados são relatados nas duas seções a seguir.

\section{Reordenação, setores, pesos das ações e rebalanceamento}

Os resultados desta seção sugerem que a ordenação pelo IS é um critério relevante para a formação das carteiras. Contudo, a redução da repetição de setores de atividade na carteira para mais diversificação e o uso de pesos diferentes obtidos por um método simples não mudam substancialmente o desempenho das novas carteiras $1 / \mathrm{N}$ assim obtidas em relação ao das originais. Finalmente, carteiras $1 / \mathrm{N}$ com rebalanceamento anual apresentam desempenho inferior ao das carteiras originais com duas séries $(N$ igual a 7 e 12), com significância estatística marginal ao nível de $10 \%$ para a diferença entre as medianas.

Carteiras $1 / \mathrm{N}$ formadas segundo a ordenação inversa pelo IS verificam se este critério faz diferença. As ações escolhidas para formar as carteiras $1 / \mathrm{N}$ foram ordenadas do menor para o maior IS, privilegiando o pior desempenho em relação ao risco. A amostra de ações é a mesma empregada nos testes principais. A Tabela 5 mostra que as médias, medianas e IS das carteiras $1 / \mathrm{N}$ formadas a partir da ação de menor IS na amostra considerada são menores do que os das carteiras $1 / \mathrm{N}$ originais retratadas na Tabela 1. Em alguns casos, as medianas são significativamente menores do que as das carteiras $1 / \mathrm{N}$ originais ao nível de 5\% (carteiras com $N$ igual a 5, 6, 12 e 13) e, em dois casos, a significância ocorreu ao nível de $10 \%$ (carteiras com $N$ igual a 11 e 16). O resultado oferece uma recomendação prática importante para o investidor, uma vez que indica que o desempenho ajustado ao risco de um quadrimestre contribui para o sucesso dessa estratégia ingênua.

Tabela 5

Ações Ordenadas do Menor para o Maior IS de Retornos Diários, entre 5/1998 e 12/2011

\begin{tabular}{lccccccc}
\hline Carteira & $\begin{array}{c}\text { Acumulado } \\
(\%)\end{array}$ & $\begin{array}{c}\text { Média } \\
(\%)\end{array}$ & $\begin{array}{c}\text { Mediana } \\
(\%)\end{array}$ & $\begin{array}{c}\text { DP } \\
(\%)\end{array}$ & IS & Wilcoxon & Prob. \\
\hline $1 / \mathrm{N}=6$ & 431 & 0,0772 & 0,0525 & 2,36 & 0,0065 & 2,07 & 0,04 \\
$1 / \mathrm{N}=7$ & 387 & 0,0733 & 0,0496 & 2,30 & 0,0050 & 1,96 & 0,05 \\
$1 / \mathrm{N}=8$ & 337 & 0,0690 & 0,0526 & 2,26 & 0,0032 & 1,39 & 0,16 \\
$1 / \mathrm{N}=9$ & 298 & 0,0659 & 0,0576 & 2,24 & 0,0018 & 1,47 & 0,14 \\
$1 / \mathrm{N}=10$ & 342 & 0,0693 & 0,0671 & 2,26 & 0,0033 & 1,61 & 0,11 \\
$1 / \mathrm{N}=11$ & 281 & 0,0646 & 0,0384 & 2,24 & 0,0012 & 1,68 & 0,09 \\
$1 / \mathrm{N}=12$ & 387 & 0,0716 & 0,0595 & 2,23 & 0,0044 & 2,14 & 0,03 \\
\hline
\end{tabular}


Tabela 5 (continuação)

\begin{tabular}{lccccccc}
\hline Carteira & $\begin{array}{c}\text { Acumulado } \\
(\%)\end{array}$ & $\begin{array}{c}\text { Média } \\
(\%)\end{array}$ & $\begin{array}{c}\text { Mediana } \\
(\%)\end{array}$ & $\begin{array}{c}\text { DP } \\
(\%)\end{array}$ & IS & Wilcoxon & Prob. \\
\hline $1 / \mathrm{N}=13$ & 374 & 0,0706 & 0,0572 & 2,22 & 0,0040 & 2,12 & 0,03 \\
$1 / \mathrm{N}=14$ & 347 & 0,0687 & 0,0546 & 2,21 & 0,0031 & 1,60 & 0,11 \\
$1 / \mathrm{N}=15$ & 321 & 0,0664 & 0,0310 & 2,19 & 0,0021 & 1,30 & 0,19 \\
$1 / \mathrm{N}=16$ & 265 & 0,0620 & 0,0441 & 2,18 & 0,0000 & 1,80 & 0,07 \\
\hline
\end{tabular}

Nota. Retornos diários (3385 observações). Acumulado é o retorno acumulado no período, DP é o desvio padrão e IS é o Índice de Sharpe definido na Equação 1. Wilcoxon é o teste de postos com sinais de Wilcoxon para a diferença entre o retorno mediano das carteiras 1/N alternativas e o de suas correspondentes na Tabela 1. Prob. é o valor de prova desse teste.

Bennet e Sias (2011) concluíram que o número de ativos necessários para a diversificação de uma carteira deve ser muito alto, mesmo com ações de diferentes setores de atividade. Novas carteiras $1 / \mathrm{N}$ compostas com o menor número possível de ações do mesmo setor de atividade para mais diversificação, respeitando o critério original de inclusão do maior para o menor IS, podem revelar se uma menor concentração por setor de atividade, como a inclusão de ações ordinárias e preferenciais da mesma empresa, afeta o desempenho das carteiras $1 / \mathrm{N}$.

Foi empregado o critério de classificação setorial da BM\&FBovespa, que consiste de 10 setores subdivididos em 43 subsetores. Empregou-se a classificação ao nível de subsetores, cuja relação completa está disponível em http://bit.ly/1pYSLaR (URL abreviado).

Percorre-se a lista com as ações que podem ser consideradas em um quadrimestre listadas do maior para o menor IS. Ao se encontrar uma ação de um subsetor de atividade que já apareceu na lista, como a ação da outra espécie de uma mesma empresa, por exemplo, move-se essa ação para o final da lista e continua-se a percorrer tal lista fazendo o mesmo procedimento, até se chegar à ação de menor IS ou se completar $N$ ações na carteira. Caso se chegue à ação de menor IS e ainda não tenha sido possível obter as $N$ ações necessárias, então passa-se a incluir as que foram deslocadas para o final da lista, seguindo-se o mesmo procedimento de mover para o final da lista aquelas que forem do mesmo setor das ações de setor repetido incluídas, até que se chegue às $N$ ações necessárias.

Não houve inclusão de ações de espécies diferentes da mesma empresa em $66 \%$, 44\% e $17 \%$ das carteiras com $N$ igual a 6,10 e 16, por exemplo, respectivamente, no método empregado nos testes principais. Não houve inclusão de ações de espécies diferentes da mesma empresa em todas as carteiras com $N$ igual a 6 e a 10 e em $88 \%$ das carteiras com $N$ igual a 16 no teste de robustez com maior diversificação setorial. Subsetores de nove dos dez setores foram incluídos em pelo menos uma carteira, excetuando-se os subsetores do setor de tecnologia da informação. Os subsetores com maior número de inclusões nas carteiras $1 / \mathrm{N}(N=16)$ com mais diversificação segundo o setor de atividade foram os de telefonia fixa e energia elétrica, com 50 inclusões cada um em 656 possíveis (41 rebalanceamentos vezes 16 ações). Os subsetores com menor número de inclusões foram os de agropecuária e de tecidos, vestuário e calçados, com apenas uma inclusão cada um em 656 possíveis. Os resultados desse e dos testes de robustez a seguir foram omitidos por limitação de espaço, mas estão disponíveis com os autores. Não houve diferença estatística significativa entre as medianas dessas carteiras e as das carteiras $1 / \mathrm{N}$ originais.

Chance et al. (2011) e Bennet e Sias (2011) afirmaram que grande parte dos investidores não possui carteiras igualmente ponderadas, embora elas sejam muito usadas nos estudos sobre a quantidade de ativos e sua relação com o risco diversificável. Além disso, esses autores mencionam estudos que sugerem que carteiras com valores diferentes para os pesos dos ativos podem apresentar benefícios quanto à diversificação em relação a carteiras igualmente ponderadas, o que é consistente com a evidência brasileira em Thomé et al. (2011), Santos e Tessari (2012) e Rubesam e Beltrame (2013), por exemplo. 
Novas carteiras formadas pelas mesmas ações presentes nas carteiras $1 / \mathrm{N}$ originais, porém com pesos diferentes para cada uma, podem verificar esse aspecto. A atribuição de pesos diferentes, como no caso da maximização por média-variância, reconhece que há informação relevante nos dados históricos empregados na estimativa dos pesos. O critério de atribuição dos pesos privilegiou as ações de maior IS no período anterior. O cálculo dos pesos segue um critério simples para não exigir que o investidor conheça o método de Markowitz (1952).

Os pesos atribuídos foram o posto da ação $i$, segundo a ordenação do maior IS (posto $N$ ) para o menor IS (posto 1), dividido pelo somatório dos postos de 1 até $N$. Os pesos são sempre os mesmos para uma carteira de tamanho $N$. Considere o exemplo de uma carteira com 6 ações (postos). A soma dos postos de 1 até 6 é igual a 21. A ação de maior IS teria posto 6 e peso $6 / 21(28,57 \%)$, a ação com o segundo maior IS teria posto 5 e peso 5/21 (23,81\%), e assim sucessivamente, até a ação com menor IS entre as 6 de maior IS, que teria peso igual a $1 / 21(4,76 \%)$.

Não há diferença significativa entre as medianas dessas carteiras ingênuas com pesos maiores para IS maiores e as das carteiras $1 / \mathrm{N}$ originais. Os resultados não sugerem que esses pesos determinados de forma proporcional ao ordenamento segundo o IS contribuam para a melhora ou piora do desempenho das carteiras 1/N. Esse resultado reforça as conclusões dos estudos brasileiros supracitados sobre os méritos da otimização de média-variância.

Finalmente, os retornos medianos das carteiras $1 / \mathrm{N}$ originais, com rebalanceamento quadrimestral, foram comparados com os de carteiras $1 / \mathrm{N}$ com rebalanceamento anual, mas não houve significância estatística ao nível de 5\%. O rebalanceamento menos frequente pode ser uma alternativa para reduzir os custos de transação e IR, e como o resultado dessas carteiras $1 / \mathrm{N}$ alternativas não foi significativamente diferente do das carteiras originais, empregou-se essa frequência para averiguar o impacto dos custos de transação e impostos.

\section{Tributos e custos de transação}

As carteiras 1/N não apresentaram retorno mediano significativamente diferente do das carteiras MVP 10\% e do Ibovespa antes de impostos. Não há razão para acreditar que isso se alteraria ao se considerar custos de transação, que afetariam todas as carteiras. Esta seção relata um estudo sobre o impacto dos custos de transação e do imposto de renda (IR) no desempenho de carteiras $1 / \mathrm{N}$. O estudo se limitou às carteiras com rebalanceamento anual, antes e depois da inclusão de custos de transação e IR, e com $N$ entre 12 e 16, por simplicidade. A formação das carteiras seguiu o critério de usar as ações de maior IS no quadrimestre anterior. A análise começou em janeiro de 1999 e estendeu-se até dezembro de 2011, para que os rebalanceamentos fossem feitos sempre no primeiro dia de negócios de cada ano. Os resultados das novas carteiras foram naturalmente inferiores às respectivas carteiras originais, sem significância estatística para a diferença entre os retornos medianos segundo o teste de postos com sinais de Wilcoxon.

O estudo, porém, sugere uma ordem de grandeza para o impacto do IR e dos custos de transação sobre o desempenho das carteiras $1 / \mathrm{N}$ com rebalanceamento anual de 1,42 pontos base por dia ou 364 pontos base por ano para os retornos médios, e de 1,63 pontos base por dia ou 419 pontos base por ano para os retornos medianos da carteira com $N$ igual a 16, por exemplo. Esses custos de transação não são desprezíveis, sendo comparáveis às taxas de administração mais elevadas entre os 52 FIAs selecionados. Contudo, não houve diferença significativa entre o retorno mediano dos FIAs, cujos retornos líquidos foram ajustados para a taxa de administração do FIA e as carteiras 1/N. Houve, ainda, uma predominância quase que total de sinais negativos para os IS tomados em relação a carteiras $1 / \mathrm{N}$ selecionadas. Apesar de seu custo de transação relativamente elevado, as carteiras $1 / \mathrm{N}$ não foram superadas pelos FIAs selecionados.

O investimento inicial simulado foi de $\mathrm{R} \$ 50.000$. A alíquota do IR foi de $15 \%$ sobre o ganho líquido com ações superiores a $\mathrm{R} \$ 20.000,00$ no mês. Os custos de transação incluíram uma taxa de corretagem de 0,5\% mais uma tarifa fixa de $\mathrm{R} \$ 25,21$ para valores de compra e venda diários acima de $\mathrm{R} \$ 3.029,38$, sugerida pela Tabela da BM\&FBovespa. O Imposto Sobre Serviços (ISS) incide sobre o 
valor de corretagem e foi considerado na alíquota de $2 \%$. A BM\&FBovespa cobrava, ainda, uma alíquota de $0,0345 \%$ a título de emolumentos aplicada sobre o volume financeiro das operações. Considerou-se, finalmente, uma taxa de custódia fixa de $\mathrm{R} \$ 6,90$ por mês.

\section{Conclusões}

O objetivo deste artigo foi examinar carteiras $1 / \mathrm{N}$ com $N$ pequeno tendo como foco o investidor sem sofisticação com pequenas carteiras de ações. A partir das ações constituintes do índice Ibovespa a cada quadrimestre, formaram-se carteiras igualmente ponderadas e de mínima variância global (MVP). O critério de inclusão das ações em uma carteira igualmente ponderada foi o ordenamento do maior para o menor Índice de Sharpe (IS). Todas as carteiras $1 / \mathrm{N}$ construídas com as ações de maiores IS no período anterior apresentaram retornos médios e medianos e IS maiores do que o do Ibovespa para retornos diários, mas o mesmo não acontece com os retornos mensais. As carteiras 1/N, porém, não apresentaram retornos medianos estatisticamente diferentes dos do Ibovespa, segundo testes não paramétricos conservadores.

A análise dos retornos ajustados ao risco não revela vantagens claras das carteiras $1 / \mathrm{N}$ sobre a MVP com limite de pesos positivos de $10 \%$. As carteiras $1 / \mathrm{N}$ não apresentam retornos estaticamente diferentes dos da MVP 10\%, o que é consistente com a afirmativa de DeMiguel et al. (2009), de que o valor de $N$ deve ser grande para que as carteiras ingênuas apresentem desempenho superior aos oferecidos por carteiras formadas por meio de técnicas de otimização. O desvio padrão das carteiras MVP 10\% estimadas é muito menor do que o das carteiras $1 / \mathrm{N}$, o que contribuiu para que sua relação retorno-risco superasse às das carteiras $1 / \mathrm{N}$, na maioria das vezes. Embora os investidores que empreguem carteiras 1/N tenham grandes chances de superar o Ibovespa, apenas em termos absolutos, mas não ajustados a risco, as chances de superar uma carteira de mínima variância formada segundo a otimização clássica de Markowitz, com limites impostos sobre os pesos, serão muito menores. As informações históricas usadas na determinação dos pesos segundo o processo de maximização de médiavariância introduz informações relevantes que resultam em pesos que levaram a um desempenho melhor do retorno ajustado ao risco dessas carteiras em relação às carteiras $1 / \mathrm{N}$. Nota-se, ainda, que o rebalanceamento das carteiras 1/N limita o downside risk. Behr et al. (2013) e Pflug et al. (2012) conjecturaram que a imposição de limites é importante e que carteiras otimizadas com pesos restritos superam carteiras $1 / \mathrm{N}$.

O retorno mediano e o IS das carteiras $1 / \mathrm{N}$ foi, pelo menos, tão bom quanto o dos 52 FIAs selecionados. Os resultados foram ajustados para as taxas de administração dos fundos. Essa evidência também é consistente com a apresentada por Thomé et al. (2011), que indicam que a carteira MVP 10\% supera a maior parte dos FIAs com os quais ela foi comparada, e tem relevância prática, uma vez que sugere que a seleção do gestor que será bem sucedido é crítica para que um FIA supere a carteira 1/N. Naturalmente, como fazer a escolha certa, a priori, é muito difícil, então, montar uma carteira $1 / \mathrm{N}$ pode ser uma boa estratégia em vez de apostar em FIAs.

Os testes de robustez indicam que a ordenação das ações para formar as carteiras $1 / \mathrm{N}$ do maior para o menor IS é relevante, mas que a exclusão, tanto quanto possível, de ações do mesmo setor de atividade e atribuir pesos maiores para ações com IS maior, por meio de uma fórmula simples, e não por maximização de média-variância, não melhora significativamente o desempenho das carteiras $1 / \mathrm{N}$. $\mathrm{O}$ rebalanceamento algumas vezes por ano pode ser importante uma vez que carteiras $1 / \mathrm{N}$ com rebalanceamento anual tiveram desempenho marginalmente inferior. Os custos de transação e o IR das carteiras 1/N não são baixos e podem ultrapassar 400 pontos base no ano, mas seu desempenho assegurou que elas não fossem superadas pelas alternativas consideradas neste artigo.

Outra implicação prática deste estudo é que ETFs que imitem carteiras $1 / \mathrm{N}$ podem ser um produto interessante. A escolha do tamanho ideal de $N$ para carteiras ingênuas está muito relacionada com o risco a que se pretende expor. Carteiras com $N$ menor ou igual a 10 podem ser aceitáveis se os 
investidores tolerarem um risco maior na busca de maiores retornos. Os mais conservadores devem optar por carteiras com $N$ maior do que 10 ou pela MVP com limite de peso de $10 \%$ por ativo, que apresenta desvio padrão bem inferior às carteiras ingênuas.

As carteiras 1/N com $N$ entre 6 e 16 não superaram a versão da MVP aqui empregada e não há razão para acreditar que superariam carteiras obtidas com modelos de otimização mais robustos e sofisticados, como alguns dos já analisados por DeMiguel et al. (2009), cujo exame transcende o escopo deste artigo. Rubesam e Beltrame (2013) e Santos e Tessari (2012) apresentam evidência brasileira que sugere que métodos mais complexos de otimização de carteiras superam a 1/N. Por outro lado, embora DeMiguel et al. (2009) tenham mostrado que carteiras 1/N com um grande número de ativos foram capazes de superar tais técnicas, seria relevante que trabalhos futuros conciliassem esses resultados para o mercado brasileiro, uma vez que há grande discrepância entre o tamanho do período e a frequência dos retornos e rebalanceamentos empregados nesses estudos.

Cabe ainda dizer que estudos futuros podem considerar outros critérios de formação de carteiras 1/N, bem como experimentos de Monte Carlo com a formação aleatória dessas carteiras a partir do universo de ações considerado, com renovação do universo de empresas para sorteio, estendendo trabalhos como o de Battaglia (2013). O universo de ações considerado é outra limitação deste trabalho, pois pode-se examinar o que acontece quando o investidor opta por ações de baixa liquidez. Finalmente, Pflug et al. (2012) e DeMiguel et al. (2009), entre outros, oferecem uma razão teórica para os resultados aqui obtidos baseados no problema dos erros nas estimativas dos parâmetros de otimização, que se torna mais severo à medida que se empregam séries históricas curtas para derivá-los, como no caso brasileiro. Os autores afirmam que, nessas circunstâncias, a carteira $1 / \mathrm{N}$ pode se sobressair, mas, ainda assim, não há porque supor que os resultados aqui obtidos se mantenham no futuro justamente porque o período amostral de 12 anos e oito meses é curto em relação aos aludidos nesses estudos.

\section{Referências}

Battaglia, T. K. (2013). Desempenho de carteiras 1/N selecionadas aleatoriamente (Dissertação de mestrado). Universidade Federal do Rio de Janeiro, Rio de Janeiro, RJ, Brasil. Recuperado de http://www.coppead.ufrj.br/upload/publicacoes/Theo_Battaglia.pdf

Behr, P., Guettler, A., \& Miebs, F. (2013). On portfolio optimization: imposing the right constraints. Journal of Banking \& Finance, 37(4), 1232-1242. doi: 10.1016/j.jbankfin.2012.11.020

Bennet, J. A., \& Sias, R. W. (2011). Portfolio diversification. Journal of Investment Management, 9(3), 74-98.

Brito, N. R. O. (1989). O efeito da diversificação de risco no mercado acionário brasileiro. In N. R. O. Brito (Org.), Gestão de investimentos (pp. 81-104). São Paulo: Atlas.

Chance, D. M., Shynkevich, A., \& Yang, T. H. (2011). Experimental evidence on portfolio size and diversification: human biases in naïve security selection and portfolio construction. Financial Review, 46(3), 427-457. doi: 10.1111/j.1540-6288.2011.00307.x

DeMiguel, V., Garlappi, L., \& Uppal, R. (2009). Optimal versus naive diversification: how inefficient is the $1 / \mathrm{N}$ portfolio strategy? The Review of Financial Studies, 22(5), 1915-1953. doi: 10.1093/rfs/hhm075

Duchin, E., \& Levy, H. (2009). Markowitz versus the Talmudic portfolio diversification strategies. Journal of Portfolio Management, 35(2), 71-74. doi: 10.3905/JPM.2009.35.2.071 
Fletcher, J. (2011). Do optimal diversification strategies outperform the $1 / \mathrm{N}$ strategy in U.K. stock returns? International Review of Financial Analysis, 20(5), 375-385. doi: 10.1016/j.irfa.2011.07.002

Jensen, M. C. (1968). The performance of mutual funds in the period 1945-1964. Journal of Finance, 23(2), 389-416. doi: 10.1111/j.1540-6261.1968.tb00815.x

Kirby, C., \& Ostdiek, B. (2012). It's all in the timing: simple active portfolio strategies that outperform naive diversification. Journal of Financial and Quantitative Analysis, 42(2), 437-467. doi: $10.1017 / \mathrm{S} 0022109012000117$

Kritzman M., Page, S., \& Turkington, D. (2010). In defense of optimization: the fallacy of 1/ N. Financial Analysts Journal, 66(2), 31-39. doi: 10.2469/faj.v66.n2.6

Levine, D. M., Stephan, D. F., Krehbiel, T. C., \& Berenson, M. L. (2005). Estatística: teoria e aplicações. Rio de Janeiro: LTC.

Markowitz, H. (1952). Portfolio selection. The Journal of Finance, 7(1), 77-91. doi: 10.1111/j.15406261.1952.tb01525.x

Modigliani, F., \& Modigliani, L. (1997). Risk-adjusted performance. Journal of Portfolio Management, 23(2), 45-54. doi: 10.3905/jpm.23.2.45

Oliveira, F. N., \& Paula, E. L. (2008). Determinando o grau ótimo de diversificação para investidores usuários de home brokers. Revista Brasileira de Finanças, 6(3), 437-461.

Pflug G. C., Pichler, A., \& Wozabal, D. (2012). The $1 / \mathrm{N}$ investment strategy is optimal under high model ambiguity. Journal of Banking \& Finance, 36(2), 410-417. doi: 10.1016/j.jbankfin.2011.07.018

Póvoa, A. (2010). Mundo financeiro: o olhar de um gestor. São Paulo: Saraiva.

Rubesam, A., \& Beltrame, A. L. (2013). Carteiras de variância mínima no Brasil. Revista Brasileira de Finanças, 11(1), 81-118.

Santos, A. A. P., \& Tessari, C. (2012). Técnicas quantitativas de otimização de carteiras aplicadas ao mercado de ações brasileiro. Revista Brasileira de Finanças, 10(3), 369-394.

Sharpe, W. F. (1966). Mutual fund performance. Journal of Business, 39(1), 119-138. doi: $10.1086 / 294846$

Sharpe, W. F. (1994). The Sharpe ratio. Journal of Portfolio Management, 21(1), 49-58. doi: 10.3905/jpm.1994.409501

Sortino, F. A., \& Price, L. N. (1994). Performance measurement in a downside risk framework. The Journal of Investing, 3(3), 59-64. doi: 10.3905/joi.3.3.59

Swensen, D. (2009). Pioneering portfolio management: an unconventional approach to institutional investment. New York: Free Press.

Thomé, C., Neto, Leal, R. P. C., \& Almeida, V. S. (2011). Um índice de mínima variância de ações brasileiras. Economia Aplicada, 15(4), 535-557. doi: 10.1590/S1413-80502011000400002 


\section{Dados dos Autores}

\section{Diogo Carneiro Santiago}

Rua Coelho e Castro, 60, 20081-902, Rio de Janeiro, RJ, Brasil. E-mail: dcssantiago@ gmail.com

Ricardo Pereira Câmara Leal

Rua Prof. Pascoal Lemme, 355, 22793-236, Rio de Janeiro, RJ, Brasil. E-mail: ricardoleal@ coppead.ufrj.br 